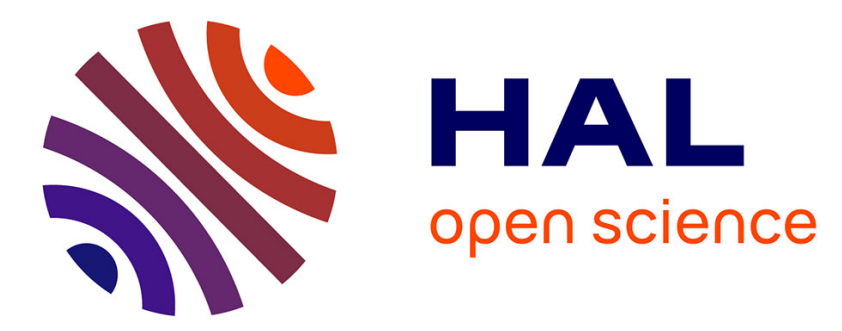

\title{
Dry Electrode Materials for Electrocardiographic Monitoring
}

\author{
Y. Gan, R. Vauche, J-F Pons, W. Rahajandraibe
}

\section{To cite this version:}

Y. Gan, R. Vauche, J-F Pons, W. Rahajandraibe. Dry Electrode Materials for Electrocardiographic Monitoring. 2018 25th IEEE International Conference on Electronics, Circuits and Systems (ICECS), Dec 2018, Bordeaux, France. pp.645-646, 10.1109/ICECS.2018.8617992 . hal-02022329

\section{HAL Id: hal-02022329 \\ https://hal.science/hal-02022329}

Submitted on 20 Dec 2021

HAL is a multi-disciplinary open access archive for the deposit and dissemination of scientific research documents, whether they are published or not. The documents may come from teaching and research institutions in France or abroad, or from public or private research centers.
L'archive ouverte pluridisciplinaire HAL, est destinée au dépôt et à la diffusion de documents scientifiques de niveau recherche, publiés ou non, émanant des établissements d'enseignement et de recherche français ou étrangers, des laboratoires publics ou privés. 


\title{
Dry Electrode Materials for Electrocardiographic Monitoring
}

\author{
Y. Gan ${ }^{1,2}$, R. Vauche ${ }^{1}$, J-F Pons ${ }^{2}$, W. Rahajandraibe ${ }^{1}$ \\ ${ }^{1}$ Aix Marseille Univ, Université de Toulon, CNRS, IM2NP, Marseille, France \\ ${ }^{2}$ WitMonki SAS, Marseille, France
}

\begin{abstract}
In this paper, a preliminary study about the most suitable dry electrode materials is done in the context of electrocardiogram (ECG) measurement systems used at home. Therefore, the electrical equivalent circuit between two electrodes through the body is developed as well as the ECG quality evaluation factors. Finally, an initial series of impedance and ECG quality measurements is presented which led to the conclusion that dry stainless steel electrodes seem to provide the best ECG signal quality.
\end{abstract}

Keywords-ECG; Dry electrode materials; Electrical Double Layer Impedance

\section{INTRODUCTION}

To diagnose heart disease which remains the most common death cause in the world with 17.3 million deaths each year [1], the 12-lead electrocardiogram (ECG) monitoring (which requires 12 wet $\mathrm{Ag} / \mathrm{AgCl}$ electrodes) is the most common used ECG acquisition method in a hospital environment. However, with this technique, the patient must stay still and electrodes must be placed by medical staff, which is hardly possible at home. Thereby, to diagnose heart disease at home, simple ECG monitoring systems must be developed. The one developed by WitMonki is a credit card format device with two electrodes where left and right thumbs have to be placed. To make the equipment widely accepted, dry electrodes without electrolytic gel have been adopted. Nevertheless, ECG signal acquisition is more sensitive to motion when dry electrodes are used. For this reason, this paper presents the on-going research works concerning the materials of the electrodes. The main objectives are 1) selecting the material which allows ECG to be as few motion sensitive as possible while keeping its dynamic high, 2) characterizing its electrical parameters, and 3) relating ECG quality and electrical characteristics as future work.

To do so, an electrical model of the impedance between two electrodes through the body is presented in Section II. Next, Section III develops the model fitting procedure and measurement results for several materials. Finally, ECG quality evaluation factors are given in Section IV, and a conclusion presents the direction for the future researches.

\section{ELECTRICAL MODELING BETWEEN ELECTRODES}

When a finger touches an electrode, a spatial region of finite thickness, usually on the order of angstroms, is formed at the surface between the material and the body fluid. It can be seen as a parallel arrangement of opposite charges called Electrical Double Layer (EDL) [2]. To model the electrical behavior of the EDL, the Constant Phase Element (CPE) [3] has been introduced and its admittance has been defined as follows:

$$
Y_{C P E}(\omega)=Q \cdot(j \omega)^{n},
$$

where $n$ is a coefficient between 0 and 1 and $\mathrm{Q}$ is a constant. Thus, when $n$ is equal to 0 , the CPE is equivalent to a resistor $\mathrm{R}$ $(R=1 / Q)$ whereas when $n$ is equal to 1 , the CPE is equivalent to a capacitor $\mathrm{C}(C=Q)$. Using the $\mathrm{CPE}$, the impedance $Z_{E E}$ seen between both electrodes can be modeled as shown in Fig. 1 where $R_{P} / 2$ in parallel to the CPE models the thumb-electrode interface and $R_{S}$ the human body resistance. Hence, the impedance $Z_{E E}$ is defined as follows:

$$
Z_{E E}(\omega)=R_{S}+\frac{R_{P}}{1+R_{P} Q(j \omega)^{n}} .
$$

The real part and the imaginary part of $Z_{E E}$ can also be formally written as:

$$
\begin{aligned}
& \operatorname{Re}\left[Z_{E E}(\omega)\right]=R_{S}+\frac{R_{P}+R_{P}{ }^{2} Q \omega^{n} \cos (n \pi / 2)}{1+2 R_{P} Q \omega^{n} \cos (n \pi / 2)+R_{P}{ }^{2} Q^{2} \omega^{2 n}}, \\
& \operatorname{Im}\left[Z_{E E}(\omega)\right]=\frac{-R_{P}{ }^{2} Q \omega^{n} \sin (n \pi / 2)}{1+2 R_{P} Q \omega^{n} \cos (n \pi / 2)+R_{P}{ }^{2} Q^{2} \omega^{2 n}},
\end{aligned}
$$

which allows $Z_{E E}$ to be represented in the Nyquist plot as shown in Fig. 2.

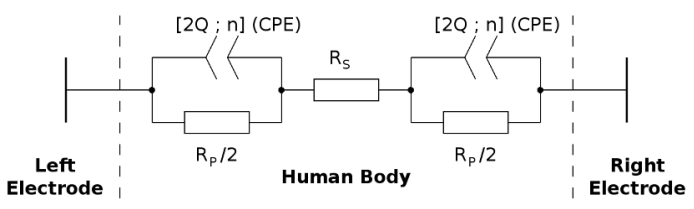

Fig. 1. The equivalent electrical circuit between the left and right electrodes.

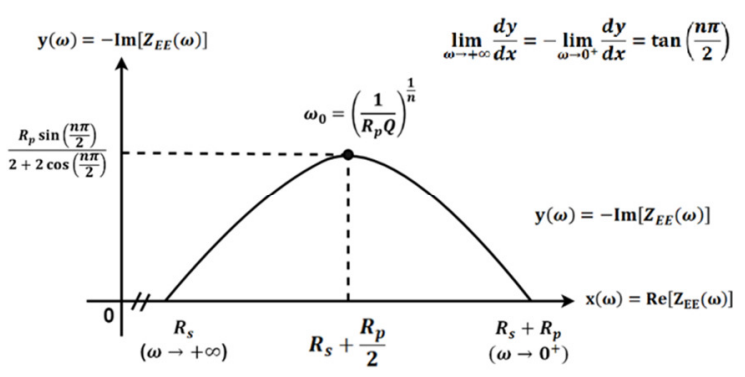

Fig. 2. Nyquist diagram of the impedance between both electrodes.

\section{FitTing PRocedure AND MEASUREMENT RESUlts}

To extract the values of $R_{P}, R_{S}, Q$, and $n$ for different materials, a first set of complex impedance measurements was obtained with the impedance tester from Metrohm France SAS between $0.1 \mathrm{~Hz}$ and $1 \mathrm{kHz}$ for several brass electrodes with a deposited layer of stainless steel (SST), platinum (Pt), chromium $(\mathrm{Cr})$, palladium $(\mathrm{Pd})$, and gold $(\mathrm{Au})$ respectively or 
without layer (BS). The modulus of the measured impedance $Z_{E E}$ is shown in Fig. 3 for each material and it appears that the higher the overall material impedance is, the noisier the measured impedances between $1 \mathrm{~Hz}$ and $100 \mathrm{~Hz}$ are. The extracted values of each component of the electrical equivalent circuit seen between both electrodes are shown in Table I for each material. To obtain them, the Scilab "datafit" function has been used on the imaginary part of $Z_{E E}$ using the quasi-Newton algorithm for several initial values of $n$ (from 0 to 1 with a step of 0.01). The other initial values were $R_{S}=\operatorname{Re}\left[Z_{E E}(2 \pi 0.1)\right], R_{P}$ $=\operatorname{Re}\left[Z_{E E}(2 \pi 1000)\right]-\operatorname{Re}\left[Z_{E E}(2 \pi 0.1)\right]$, and $Q=0.05 \mu \Omega^{-1} . s^{n}$. The solution which gives the lowest error has been chosen. Finally, to validate the accuracy of the model, the coefficient of determination $\mathrm{R}^{2}$ computed from the measured and the modeled $Z_{E E}(\omega)$ is also given in Table I. The model can be accepted since the values of $R^{2}$ were all close to 1 .

TABLE I. SUMMARY OF THE FITTED PARAMETER RESULTS

\begin{tabular}{|c|c|c|c|c|c|c|}
\hline & BS & SST & Pt & Cr & Pd & Au \\
\hline $\mathrm{Rs}(\Omega)$ & 5542 & 4325 & 6450 & 10300 & 1000 & 33900 \\
\hline $\mathrm{Rp}(\mathrm{M} \Omega)$ & 1.00 & 1.16 & 1.12 & 1.35 & 1.18 & 1.44 \\
\hline $\mathrm{n}$ & 0.62 & 0.58 & 0.66 & 0.55 & 0.68 & 0.62 \\
\hline $\mathrm{Q}\left(\mu \Omega^{-1} \cdot \mathrm{s}^{\mathrm{n}}\right)$ & 0.20 & 0.25 & 0.16 & 0.24 & 0.12 & 0.09 \\
\hline$R^{2}$ & 0.997 & 0.994 & 0.998 & 0.999 & 0.987 & 0.970 \\
\hline
\end{tabular}

\section{ECG QUALITY EVALUATION FACTORS}

An ECG signal obtained through clinical wet electrodes with electrolytic gel was used as a reference to compare the ECG signal quality from the dry electrodes. These two signals were recorded simultaneously as shown in Fig. 4. A radar chart was then produced by gathering several performance metrics for each material as seen in Fig. 5. The metrics were normalized to guarantee that their values lay within the same range. In this chart, the smaller a polygon area is, the higher the ECG signal quality is. The metrics used can be divided into two groups; one considering the comparison between the ECG signal obtained with experimental electrodes (denoted $x$ ), and the reference one (denoted $y$ ), another only considering the experimental signal itself. In the first group, the reciprocal of the cross-correlation coefficient and the Root-Mean-SquareError (RMSE) were defined as follows:

$$
\begin{gathered}
1 / \operatorname{cov}(x, y)=\frac{\sqrt{\sum_{n=1}^{N}[x(n)-\bar{x}]^{2} \times \sum_{n=1}^{N}[y(n)-\bar{y}]^{2}}}{\sum_{n=1}^{N}[x(n)-\bar{x}] \times[y(n)-\bar{y}]}, \\
R M S E=\sqrt{\frac{\sum_{n=1}^{N}[x(n)-y(n)]^{2}}{n}} .
\end{gathered}
$$

The RMSE was calculated for two frequency bands $(5 \mathrm{~Hz}-$ $25 \mathrm{~Hz}$, and $25 \mathrm{~Hz}-40 \mathrm{~Hz}$ ). The second group consists of the standard deviation in low-frequency range (less than $2 \mathrm{~Hz}$ ) and the Power Spectrum Density (PSD) for three frequency bands $(45 \mathrm{~Hz}-55 \mathrm{~Hz}, 40-150 \mathrm{~Hz}$, and $>150 \mathrm{~Hz})$. Standard deviation, RMSE and cross-correlation mainly represent the motion sensitivity of the electrode, while PSD quantify noise. Finally, the radar chart indicated that the stainless steel is the bestsuited material for ECG signal acquisition.

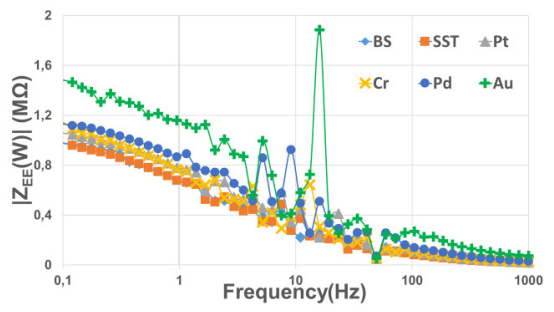

Fig. 3. Measured modulus values of $\mathrm{Z}_{\mathrm{EE}}$.

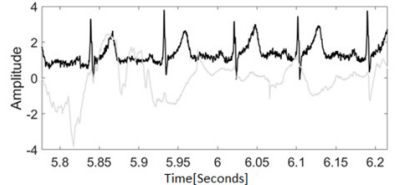

(a)

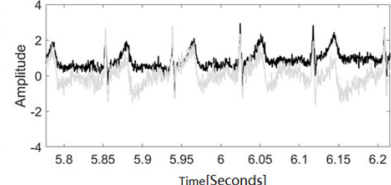

(b)
Fig. 4. Reference (black line) and experimental (gray line) ECG signals obtained with Au electrodes (a) and SST electrodes (b).

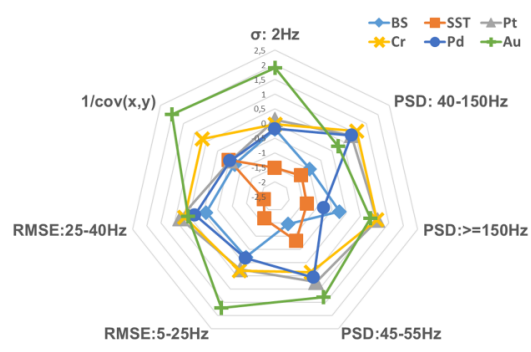

Fig. 5. Radar chart of ECG quality indicators

\section{CONCLUSION}

In this paper, the on-going research works related to the selection of the most suitable dry electrodes material for ECG monitoring systems used at home have been presented. In addition, to identify the materials and the associated electrical characteristics which allow high-quality ECGs to be obtained, an equivalent electrical circuit of the impedance between two electrodes through the human body using the CPE has been presented. Next, the series of impedance measurements allowed the parameters to be computed for each material and the accuracy of the model to be evaluated. Finally, several performance metrics for the chosen materials were defined and plotted in a radar chart to visualize the ECG signal quality, from which the stainless steel has been designated as the bestsuited electrode for ECG signal acquisition, unlike the gold. Finally, complementary study showed that the ECG signal quality could be related to the $\mathrm{Q}$ value of the CPE. Therefore, an in-deep measurement campaign must be done in the future to confirm these observations.

\section{REFERENCES}

[1] E. J. Benjamin et al., Heart Disease and Stroke Statistics-2017 Update: A Report From the American Heart Association, vol. 135, no. 10. 2017.

[2] H. Wang and L. Pilon, "Accurate simulations of electric double layer capacitance of ultramicroelectrodes," J. Phys. Chem. C, vol. 115, no. 33, pp. 16711-16719, 2011.

[3] J.-B. Jorcin, M. E. Orazem, N. Pébère, and B. Tribollet, "CPE analysis by local electrochemical impedance spectroscopy," Electrochim. Acta, vol. 51, no. 8-9, pp. 1473-1479, 2006.

[4] S. G. K. Patro and K. K. sahu, "Normalization: A Preprocessing Stage," Iarjset, pp. 20-22, 2015. 